\title{
Why Vitamin C Could Be an Excellent Complementary Remedy to Conventional Therapies for Breast Cancer
}

\author{
Michela Codini 1 \\ Department of Pharmaceutical Science, University of Perugia, 06100 Perugia, Italy; michela.codini@unipg.it; \\ Tel.: +39-075585905
}

Received: 18 September 2020; Accepted: 6 November 2020; Published: 9 November 2020

\begin{abstract}
The most frequent cancer in women is breast cancer, which is a major cause of death. Currently, there are many pharmacological therapies that have made possible the cure and resolution of this tumor. However, these therapies are accompanied by numerous collateral effects that influence the quality of life $(\mathrm{QoL})$ of the patients to varying degrees. For this reason, attention is turning to the use of complementary medicine to improve QoL. In particular, there are increased trials of intravenous injection of vitamin $C$ at high doses to enhance the antitumor activity of drugs and/or decrease their side effects. This review intends to underline the anticancer mechanisms of vitamin $\mathrm{C}$ that could explain its efficacy for treating breast cancer, and why the use of vitamin $C$ at high doses could help patients with breast cancer to enhance the efficacy of pharmacological therapies and/or decrease their side effects.
\end{abstract}

Keywords: ascorbic acid; breast cancer; anti-cancer mechanisms; reactive oxygen species; comblementary medicine

\section{Introduction}

Worldwide, breast cancer continues to be the most frequent cancer in women. The annual global incidence is over 2 million cases per year, and it causes one of the highest numbers of deaths related to cancer among women as reported by the World Health Organization (WHO) in 2018. In the European Union (EU), breast cancer is the second most frequent cause of death for cancer in women, in spite of the positive trend of mortality from the 1990s [1].

Breast cancer is a multifactorial pathology involving genetic mutations, hormonal disturbances, lifestyle, and family background of breast and ovarian cancer [2]. Having a mother, sister, or daughter (first degree relative) with breast cancer approximately doubles the risk of developing the same type of cancer, and having two first degree relatives increases the risk five-fold. In addition, women with a family background of breast cancer in the male component of the family present an increased risk of breast cancer [2].

Breast cancer is the common term for a set of breast tumor subtypes (most of these are epithelial tumors of ductal or lobular origin), with distinct molecular and cellular origins, defined by distinct pathology, sensitivity to therapy, and molecular characteristics. Breast tumors have been classified into four different subtypes on the basis of the condition of receptors, in particular progesterone receptor (PR), estrogen receptor (ER), and human epidermal growth factor 2 (HER2). The first subtype is luminal A, which is ER and/or PR receptor positive and HER2 negative. The second subtype is luminal $\mathrm{B}$, which is ER and/or PR receptor positive and HER2 positive. The third subtype is HER2 positive, which is ER/PR negative and HER2 positive; and last one is basal-type tumors, with all the receptors negative [3]. 
Tumor heterogeneity has become an important clinical feature for diagnosis and therapeutic decision-making. In the EU, the mortality for breast cancer has declined, thanks to early detection and efficient systemic therapies. Recently, there has been an increase in the number of therapies able to save the life of patients affected by breast cancer. Indeed, there are different treatments that can destroy the cancerogenic cells. Unfortunately, each of these treatments is accompanied by a series of collateral effects both in the early and late stages of the disease. These collateral effects are different and depend on the particular drug and its dose and time of treatment [4]. The adoption of complementary medicine to increase the quality of life $(\mathrm{QoL})$ can be considered an important adjunct during treatment. These complementary therapies should be used in women with a lower QoL and with an early stage of cancer [5]. In this case the results of these complementary therapies could give a better QoL to these patients [6]. In this review, the use of vitamin $C$ as a complementary remedy in breast cancers is analyzed.

\section{Chemistry and Biochemistry of Vitamin C}

Ascorbic acid is a water-soluble carbohydrate similar to glucose. However, unlike glucose, it contains the highly reactive "ene-diol" group. This group transforms a relatively inactive sugar to a powerful reducing agent in aqueous solution, which readily donates one or two electrons to radicals and oxidants, generating the relatively stable monodehydroascorbate (MDHA) radical, and the fully oxidized dehydroascorbic acid (DHA). Both DHA and MDHA can be reversibly reduced to ascorbate, as shown in Figure $1[7,8]$.
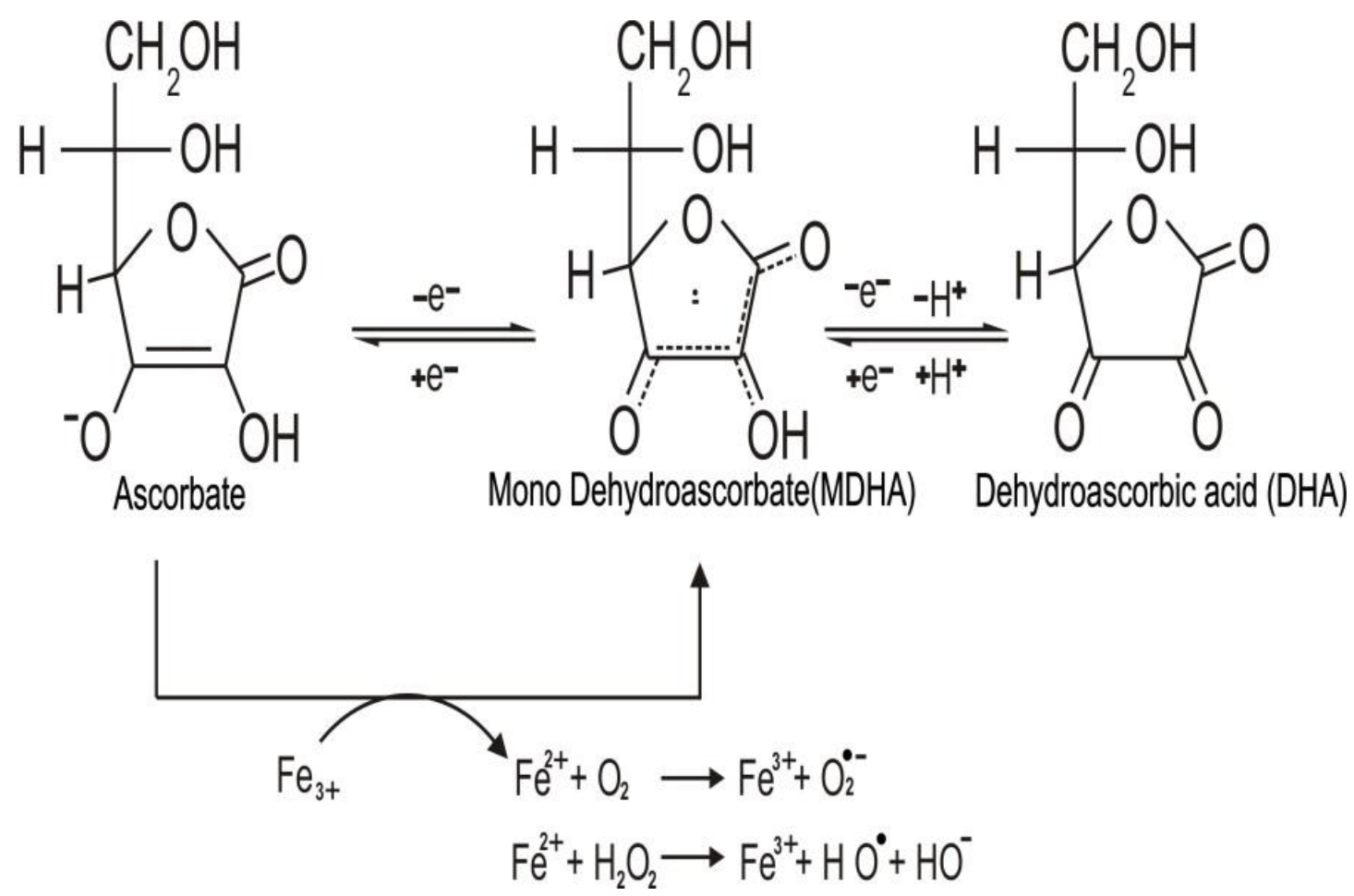

Figure 1. The three redox states of vitamin C (ascorbate, fully reduced form; mono dehydroascorbate, (MDHA), mono-oxidized form; dehydroascorbic acid (DHA), fully oxidized form). Ascorbate can donate one or two electrons to radicals and oxidant agents, forming MDHA and DHA, thus acting as a reducing agent. In the presence of metal ions such as iron, ascorbate can also reduce them and exert pro oxidant effects leading to formation of the superoxide radical $\left(\mathrm{O}_{2}{ }^{\bullet-}\right)$, hydrogen peroxide $\left(\mathrm{H}_{2} \mathrm{O}_{2}\right)$, and hydroxyl radicals ( $\left.\mathrm{HO}^{\bullet}\right)$. 
DHA is transported inside the cell by sodium vitamin C transporters 1 and 2 (SVCT1 and SVTC2, respectively) [9]. Inside the cell, DHA can be degraded to 2,3-diketogulonate, oxalate, and $L$-threonate that can be discarded by the kidney [10].

Oxidation of ascorbate by free radicals or reactive oxygen species (ROS) can be performed inside or outside the cell. Therefore, the antioxidant action of ascorbate can decrease the concentration of ROS [11]. On the other hand, when injected intravenously, ascorbate can reach millimolar concentrations, which lead to its action as a pro oxidant [12]. The pro oxidant activity is due to an association with metal ions such as $\mathrm{Fe}^{3+}$ and $\mathrm{Cu}^{2+}$ that can be chelated by ascorbate [13]. In the presence of oxygen-reduced iron, ions react with hydrogen peroxide $\left(\mathrm{H}_{2} \mathrm{O}_{2}\right)$ to develop reactive hydroxyl radicals $\left(\mathrm{HO}^{\bullet}\right)$ or peroxide ions $\left(\mathrm{O}_{2}{ }^{\bullet-}\right)$ by stimulating the reaction of Fenton (Figure 1) and Haber-Weiss chemistry $[14,15]$.

Vitamin $C$ is an crucial cofactor for many iron- and copper-containing enzymes due to its ability to maintain these transition metals in the reduced state in which the activity of these enzymes is optimized [16].

Vitamin C-dependent enzymes are classified into two groups: copper-containing monooxygenases and iron-containing and $\alpha$-ketoglutarate-dependent dioxygenases ( $\alpha$ KGDDs). $\alpha$ KGDDs uses oxygen and $\alpha$-ketoglutarate as co-substrates while producing $\mathrm{CO}_{2}$ and succinate. Among the reactions catalyzed by $\alpha$ KGDDs are a wide range of hydroxylation reactions such as those involved in collagen synthesis, carnitine synthesis, noradrenaline synthesis, demethylation of protein, DNA and RNA, and hypoxia-inducible factor $1 \alpha(\mathrm{HIF} 1 \alpha)$ stability. Thus, vitamin $\mathrm{C}$ regulates a variety of fundamental biological processes [13].

In nearly all mammals, ascorbic acid is synthesized in the kidney or liver using glucose from the blood by a number of reactions, as shown in Figure 2. Each reaction, with exclusion of the last one, is regulated by a specific enzyme. In the last reaction, the 2-keto- $L$-gulonolactone after being synthesized is transformed into ascorbic acid. 
D- GLUCOSE - 1 - P

$\downarrow$ UDP - glucose pyrophosphorylase

UPD - D - GLUCOSE

$\downarrow$ UDP - glucose dehydrogenase

UPD - D - GLUCURONATE

UDP - glucuronate pyrophosphorylase

D - GLUCURONATE - 1 - $P$

glucuronate -1 - P - phosphatase

D - GLUCURONATE

glucuronate reductase

L - GULONATE

$\downarrow$ L - gulono - 1,4 - lactone hydrolase

L - GULONO - 1,4 - LACTONE

* L - gulono - 1,4 - lactone oxidase

2 - KETO - L - GULONO - 1,4 - LACTONE

spontaneous

ASCORBATE

Figure 2. Vitamin C synthesis. The enzyme L-gulono-1,4-lactone oxidase is missing in humans and prevents them from producing ascorbic acid from glucose.

In humans, mutations dating from millions of years ago have destroyed the ability to synthesize $L$-gulonolactone oxidase, which is an enzyme necessary to transform $L$-gulonolactone into 2-keto- $L$-gulonolactone [12]. This is a clear example of a genetic disease that has previously been considered an avitaminosis.

Since humans are unable to synthesize vitamin $C$, this is required as an essential dietary supplement [17]. The recommended supplementary dose for an adult is about $100 \mathrm{mg}$ per day in order to generate a 50 micromolar concentration of vitamin $C$ in the plasma. Nonetheless, the concentration of vitamin $C$ is different in different tissues. Circulating leucocytes, pituitary gland, adrenal glands, liver, brain, and skeletal muscle accumulate higher levels of vitamin $C$ than plasma [18]. An elevated 
concentration of vitamin $C$ in cells seems to indicate the need of ascorbate as a cofactor or to decrease the levels of ROS [19].

\section{Anticancer Mechanisms of Vitamin C}

The increased understanding of the role of ascorbate in the cell together with the molecular mechanisms of cancer development has led to a number of interesting hypotheses regarding the mechanism of vitamin $C$ anti-cancer activity.

The importance of vitamin $C$ in curbing the development of cancer metastasis has been related to its role in collagen synthesis, which is decreased when there is a lack of vitamin C [20]. Indeed, it has been observed that the changes of the stroma surrounding a tumor are identical to those observed in scurvy. Thus, a dense stromal consistency may represent a physical barrier against the spread of neoplastic cells encapsulating them with a dense fibrous tissue. This result can be achieved by high doses of vitamin C. Moreover, vitamin C enhances intercellular ground substance resistance to local infiltration. Hence, it is important to maintain the synthesis of collagen at the right levels by using vitamin $C$ to contrast the development of metastasis [21]. This hypothesis was also supported by the work of Ewan Cameron and Rotman, who suggested that vitamin C inhibits the enzyme hyaluronidase, which decreases the disruption of the tissue and proliferation of cancer cells [22].

It has also been proposed that vitamin $C$ is capable of inhibiting the synthesis of series 2 prostaglandins in cancer cells [23]. These bioactive lipids are known to stimulate cell proliferation, migration, and angiogenesis. Among them, prostaglandin E2 (PGE2) is highly expressed in many solid tumors [24]. In addition, vitamin C counteracts cell proliferation by stabilizing transcription factor protein 53 (P53) [25]. Kim et al. claim that the presence of p53 may represent one of the reasons for differing ascorbate cytotoxicity among cancer cell lines [26].

The structural similarity between vitamin $C$ and glucose facilitates the entry of vitamin $C$ through glucose transporters 1 (GLUT1). Normally, cancer cells have increased expression of GLUT1 transporters due to their increased glucose requirement. The increase in GLUT1 transporters favors the internalization of vitamin $C$ into the cancer cell and promotes its action as a selective, nontoxic drug [12].

In the 2000s, experiments performed in cell culture showed that millimolar vitamin C plasma concentration can kill cancer cells via the pro-oxidative activity of ascorbate, which produces $\mathrm{H}_{2} \mathrm{O}_{2}$ and $\mathrm{OH}^{\bullet}[27,28]$.

Iron ions are important for the pro-oxidative activity of vitamin C, and, interestingly, the concentration of labile iron is increased in the microenvironment of tumor cells, which leads to a higher level of labile iron in tumor cells compared to control cells [29].

Furthermore, extracellular $\mathrm{H}_{2} \mathrm{O}_{2}$ can contribute to increase the level of extracellular DHA that after entering the cell can increase the intracellular oxidative microenvironment. DHA is internalized in tumor cells that express high amounts of GLUT1 and generates intracellular oxidative stress due to the reduction of DHA back to ascorbate. This reaction reduces the concentration of antioxidants inside the cells and increases the levels of endogenous ROS causing oxidative cell damage [30].

The anti-tumor effects of vitamin C are not only confined to the stimulation of ROS. It has been suggest that vitamin $C$ enhances the activity of ten-eleven translocation (TET) enzymes through which it can play a role in reprogramming the cells and in the regulation of cell growth. TET enzymes catalyze the oxidation of 5-methylcytosine $(5 \mathrm{mC})$ to 5 -hydroxymethylcytosine $(5 \mathrm{hmC}), 5$-formylcytosine $(5 \mathrm{fC})$, and 5-carboxylcytosine $(5 \mathrm{caC})$ with the consequence of methylating the DNA and increasing the expression of tumor suppressor genes [31,32]. Vitamin C, as a cofactor, can bind directly to TET enzymes, producing $\mathrm{Fe}^{2+}$ from $\mathrm{Fe}^{3+}$, which is necessary for TET activity. Compared to other reducing agents able to increase the TET activity, vitamin $C$ is the most efficient one [33].

Therefore, the restoration of TET activity by vitamin $C$ underlines its role in cancer epigenetic reprogramming that includes DNA hypermethylation, which mainly occurs in the promoter regions, and in particular in the CpG island [34]. 
Another anticancer mechanism of vitamin C occurs through the down-regulation of HIF- $1 \alpha$. Solid tumors are often characterized by low levels of oxygen and high expression levels of hypoxia-inducible factor 1 (HIF1). HIF1 is a transcription factor found in many types of cancers and is composed of HIF- $1 \alpha$ and HIF- $1 \beta$ subunits. HIF- $1 \beta$ is a constitutive subunit, whereas the HIF- $1 \alpha$ subunit is regulated by $\mathrm{O}_{2}$ concentration. $\mathrm{O}_{2}$ regulates HIF- $1 \alpha$ activity through HIF hydroxylases that require ascorbate as a cofactor. Thus, vitamin C, through the regulation of the HIF- $1 \alpha$ subunit, down-regulates HIF1 and the expression of HIF1-dependent genes that are important to activate angiogenesis, glycolysis, resistance to chemotherapy, and the stimulation of a stem cell phenotype, with the consequence of activating metastasis and the growth of a tumor [35-37].

Ascorbate can also stimulate the immune system to increase resistance against pathogens. Recently, Wang-Jae Lee reported that ascorbate suppresses the synthesis of interleukin 18 (IL-18), which is a regulator for various type of tumors [38]. The expression of IL-18 is correlated positively with different types of tumors [39]. IL-18 can increase the synthesis of interferon-gamma (IFN- $\gamma$ ) in natural killer (NK) cells, T cells, and activated macrophages [40]. Thus, ascorbate may be efficacious against cancer by decreasing the expression of IL-18, which is able to regulate the escape of different tumor cells, including breast cancer cells, from the immune system.

Finally, yet importantly, vitamin $C$ exhibits anti-inflammatory functions via the modulation of cytokine levels [41]. For example, a concentration of $20 \mathrm{mM}$ ascorbate inhibited the synthesis of interleukin 6 (IL-6) and tumor necrosis factor alpha (TNF- $\alpha$ ) in monocytes without changing the levels of interleukin 1 (IL-1) nor interleukin 8 (IL-8) [42]. The same concentration of ascorbate reduced interleukin 2 (IL-2) production in lymphocytes with no changes in the levels of TNF- $\alpha$ and IFN- $\gamma$. In cancer patients, ascorbate at millimolar concentrations has been shown to decrease inflammation through suppression of cyclooxygenase $2(\mathrm{COX}-2)$ and activation of nuclear factor $\mathrm{k}$-light-chain-enhancer of activated B cells (NF- $\kappa B$ ) in endothelial cells [43]. NF- $\kappa B$ is a transcription factor that regulates gene expression in inflammation processes. A low concentration of ascorbate $(0.2 \mathrm{mM})$ increases the expression of NF-kB in Jurkat T-cells [44]. In human cells, ascorbate inhibits TNF- $\alpha$ activation of NF- $\kappa B$ in a dose-dependent manner and can also decrease the synthesis of granulocyte-macrophage colony-stimulating factor (GM-CSF), interleukin 3 (IL-3), and interleukin 5 (IL-5) [45]. It is known that inflammation can regulate angiogenesis, tumor development, tumor proliferation, metastasis, and resistance to therapy [46]. The main vitamin C anticancer mechanisms are summarized in Figure 3.

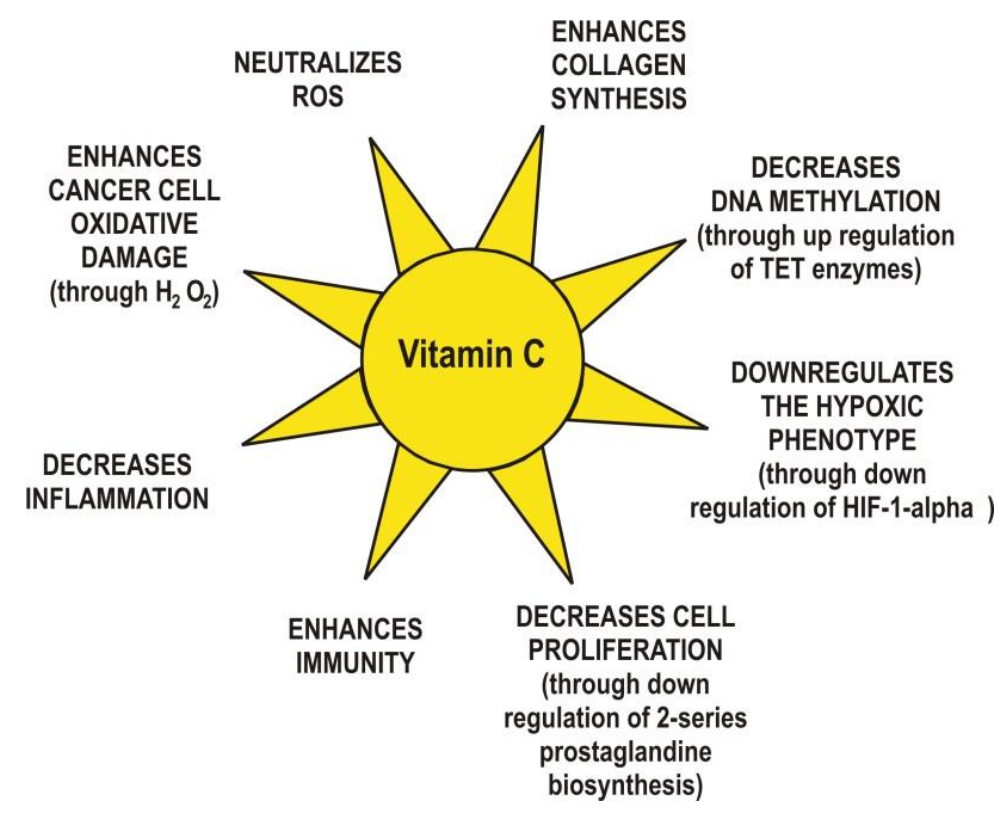

Figure 3. The main anticancer mechanisms proposed for vitamin C. 


\section{Vitamin C Effects in Breast Cancer Cell Lines and Human Mammary Tumor Xenografts}

Although data are limited for breast cancer in vivo, in human breast cancer cell lines, vitamin $\mathrm{C}$ has been frequently reported to induce apoptosis without having a significant impact on normal cells [47]. Additional data are available regarding the synergistic effect of vitamin $C$ with chemotherapy drugs. Kurbacher et al. investigated the possible synergistic effect between vitamin $C$ and some chemotherapeutics used in breast cancer therapy. They treated two human breast cancer cell lines, MCF-7 and MDA-MB-231, with $1 \mu \mathrm{M}$ and $100 \mu \mathrm{M}$ of ascorbate and with the chemotherapics doxorubicin, cisplatin, and paclitaxel. Even if the concentrations of ascorbate were in a normal range, the effect was synergistic with doxorubicin at $1 \mu \mathrm{M}$ and $100 \mu \mathrm{M}$ concentrations in MCF-7 and MDA-MB-231. Moreover, in the MDA-MB-231 cells, the effect was dose-dependent. In MCF-7 cells, ascorbate was also synergistic with cisplatin at $1 \mu \mathrm{M}$ and $100 \mu \mathrm{M}$ concentrations, while in MDA-MB-231 cells, only $100 \mu \mathrm{M}$ was effective. Neither concentration of vitamin $\mathrm{C}$ improved the activity of paclitaxel in MCF-7 cells, although the lower concentration had a synergistic effect and the higher concentration had an additive effect in MDA-MB-231 cells [48].

Interestingly, Lee et al. showed that a high-dose of vitamin $C$ mediated anti-proliferative effects on various anticancer drug-resistant breast cell lines, including tamoxifen-resistant (TAM-R) MCF-7, long-term estrogen-deprived (LTED) MCF-7, docetaxel-resistant MCF-7, docetaxel-resistant MDA-MB-231, doxorubicin-resistant MCF-7, and doxorubicin-resistant MDA-MB-231 cells. Elevated amounts of vitamin C significantly decreased the cell growth of TAM-R, doxorubicin-resistant MCF-7, and LTED MCF-7, as observed in the MCF-7 cells. Moreover, vitamin C only exerted a slight effect on the normal breast epithelial cells, MCF10A. In addition, anti-proliferative effects were observed at high-doses of vitamin $C$ in doxorubicin-resistant MDA-MB-231 cells and docetaxel-resistant MCF-7 cells, as effectively as in MDAMB-231 cells. Furthermore, the catalase activity of TAM-R MCF-7, LTED MCF-7, docetaxel-resistant MCF7 and MDA-MB-231, and doxorubicin-resistant MCF-7 cells was decreased significantly in comparison to that of MCF10A cells. Therefore, these results indicate that vitamin $C$ at a high dose has a selective anti-proliferative effect on chemotherapy-resistant breast cancer cells. Furthermore, an additive anti-cancer effect when combined with conventional agents was also observed. This provided important evidence that high-dose vitamin $C$ is a promising therapeutic drug, especially when considering that patients with advanced breast cancer ultimately develop resistance to conventional agents [49].

It has been found that an auranofin/vitamin $C$ combination exerted a synergistic and $\mathrm{H}_{2} \mathrm{O}_{2}$-mediated cytotoxicity toward MDA-MB-231 cells and other breast cancer cell lines. The anticancer potential of auranofin/vitamin C combinations was confirmed in vivo using MDA-MB-231 xenografts in mice without notable side effects [50].

Zeng et al. showed that high doses of vitamin $C$ injected intraperitoneally inhibits metastasis of human breast cancer xenografts in nude mice by inhibiting the epithelial-mesenchymal transition [51].

The level of vitamin $C$ at $100 \mu \mathrm{M}$ in the plasma can be obtained by oral administration. This concentration is able to inhibit triple-negative breast cancer (TNBC) xenograft metastasis in vivo and TNBC cell invasion in vitro [52]. An epigenetic hallmark of breast cancer and other cancers is the loss of 5-hydroxymethylcytosine (5hmC) [53]. Vitamin C at concentration of $100 \mu \mathrm{M}$ can bring a $5 \mathrm{hmC}$ level in TNBC cells similar to those of non-cancerous epithelial breast cells [54].

Although few studies of vitamin $C$ and breast cancer metastasis have been performed in human patients, in vivo animal models support the inhibition of metastasis by administration of vitamin C. For example, vitamin $C$ administrated orally stops the metastasis of murine breast cancer in Gulo knockout mice, which, similarly to humans, cannot synthesize vitamin C [55].

Park S et al. showed that IL-18 promotes the expression of transferrin, which positively regulates cell growth and proliferation in breast cancer cells. This suggest that ascorbate can act against breast cancer, decreasing the expression of IL-18. One of the physiological roles of IL8 is to regulate the escape of various cancer cells, including breast cancer cells, from the immune system [56]. 
De Francesco et al. reported a synergic effect between vitamin $C$ and dodecyl-tri-phenylphophonium (d-TPP) on eradicating breast cancer stem cells (CSCs). In that research, MCF-7 and MB-231 breast cancer cells were treated with d-TPP, an inhibitor of mitochondrial respiration and ATP production. It has been observed that this TPP derivative not only switches the energy pathway towards the glycolytic pathway in these cancer cells but also increases their sensitivity to other metabolic inhibitors like vitamin $C$ and 2-deoxy-D-glucose (2-DG) (glycolysis inhibitors), and doxycycline, niclosamide, and berberine (OXPHOS inhibitors). Therefore, that research has shown that vitamin $\mathrm{C}$ can present a synergic effect with that of other glycolytic and OX-PHOS inhibitors on the propagation of CSCs. Furthermore, it has been demonstrated that vitamin $C$ is a potential molecule to target the pathway of glycolysis for the effect on CSCs [57]. Tsao C. analyzed the effect in mice of vitamin C on the growth of a human mammary tumor. The addition of ascorbic acid in the drinking water resulted in a significant reduction in the growth of the implanted tumor. The same result was obtained with oral or intraperitoneally administration of a mixture of ascorbic acid and cupric sulfate. No effects were obtained if ascorbic acid and cupric sulfate were administrated individually [58].

\section{Vitamin C Effects In Vivo Treatment of Cancer in Human}

The use of vitamin C for the treatment of cancer was first reported in the 1950s; its involvement in collagen synthesis was the basis to hypothesize that ascorbate replenishment would protect normal tissue to develop cancers and metastasis [59]. In addition, cancer patients show low levels of vitamin C, and administration of vitamin C can improve the immune system [60].

In 1976, Pauling and Cameron published the results of a trial conducted on 100 terminal cancer patients who were given $10 \mathrm{~g} /$ day of intravenous vitamin $\mathrm{C}$ (IVC) for about 10 days, followed by oral administration of $10 \mathrm{~g} /$ day of vitamin $C$ thereafter. A control group of about 1000 cancer patients did not receive vitamin $C$ in any form. Their work showed a 4.2-fold enhanced survival time in the vitamin $\mathrm{C}$ treated patients compared with the control group.

Two years later, a retrospective analysis of this study demonstrated that $22 \%$ of patients pronounced as terminal patients had a survival time greater than 1 year compared with $0.4 \%$ in the control group [4].

Several clinical studies have investigated the effect of vitamin C on QoL in patients affected by breast cancer $[61,62]$.

In a Korean study, IVC therapy significantly ameliorated global QoL scores, with a reduction of nausea and vomiting, fatigue, and an increased appetite [63]. A German study compared patients with breast cancer undergoing IVC therapy with a control group that only received standard therapy. Patients receiving IVC therapy showed an improvement in many clinical symptoms. No collateral effects caused by ascorbate were noticed, with no modifications in tumor status compared to controls [64].

Hoffer et al. described a phase I clinical trial in patients with advanced cancer, receiving up to $1.5 \mathrm{~g} / \mathrm{kg}$ body weight of IV ascorbate every week, 3 times per week. No adverse effects were observed at any dose, and in two patients the disease was stabilized [65].

Several patients treated with IVC for more than a year have shown substantially reduced grade 1 and 2 side-effects as compared to the control group [66]. Later, Riordan et al. demonstrated that a therapy with $150-710 \mathrm{mg} / \mathrm{kg} /$ day ascorbate for up to eight weeks is safe as long as the patient has no history of kidney stone formation [67].

Hoffer et al. described a study in which patients with different cancer types were treated with IVC and chemotherapy. Vitamin C $(1.5 \mathrm{~g} / \mathrm{kg})$ was administered three times a week during the weeks in which chemotherapy was given, and with at least one day off during the weeks when chemotherapy was not given. Increased energy, functional improvement, and transient stable disease were observed in patients [68].

Some authors have raised fears that vitamin $C$ supplementation might compromise the efficacy of standard therapies because of its antioxidant properties and its accumulation in tumors [69, 70]. However, many studies show that, at high concentrations, vitamin $C$ does not interfere with standard therapies and may increase efficacy in some situations [38,71-73]. This result is sustained by 
meta-analyses of clinical studies that show no interference between antioxidant supplementation and efficacy of chemotherapic drugs [74,75].

\section{Why Should Vitamin $\mathrm{C}$ be Used in Breast Cancer Therapy?}

Several publications indicate the role of vitamin $C$ as a therapeutic compound in cancer patients, including breast cancer. In particular, the effects of vitamin $C$ treatment were effective in reducing pain, increasing QoL, and increasing appetite [76]. Furthermore, some patients increased their survival time, and vitamin $C$ was an alternative therapeutic strategy for those suffering from chemotherapy. Vitamin $C$ seems to act by reducing oxidative stress, which is one of the most relevant side-effects of chemotherapy and radiotherapy. In fact, the metabolism of tumor cells, radiotherapy, and chemotherapy increase the level of ROS, inducing oxidative stress [64]. The level of vitamin C is related to the stage of the disease; patients with an higher stage of disease showed a lower level of vitamin $C$, whereas patients with a lower stage of disease showed a higher level of vitamin $C[77,78]$. An interesting study was performed to evaluate the effects of IVC on patients with primary non-metastasized breast cancer treated with antineoplastic drugs. The efficacy of IVC treatment was equivalent to those obtained with chemotherapy and radiotherapy, but with no side-effects [66]. As reported previously, the patients treated with IVC had a better QoL that could improve the immune system.

A meta-analysis study of vitamin $C$ and survival among women with breast cancer concluded that post-diagnosis therapy with vitamin C may be related to a reduced risk of mortality. Vitamin C administration can significantly reduce the risk of mortality, including the mortality specifically caused by breast cancer [79].

Breast cancer progression is increased by tumor hypoxia that affects angiogenesis, metastatic activity, and cell proliferation [80]. HIF-1 $\alpha$ that is responsible for the observed effects is a target of antitumor action of vitamin C. HIF-1-alfa regulates cancer cell metastasis that is the major cause of death for patients with breast cancer [81]. Vitamin C is a cofactor of the enzyme HIF prolylhydroxylase, which is necessary for the degradation of HIF-1 $\alpha$ [82].

By studying the molecular mechanisms behind breast cancer development, it has been realized that many of the anticancer mechanisms of vitamin $C$ can be useful for this type of cancer. For example, breast cancer cells are sensitive to hydrogen peroxide generated from pharmacological ascorbate.

As described above, vitamin $C$ regulates the activity of TET enzymes, which is physiologically important to reprogram cells and to control cellular growth. Furthermore, it has been reported that the levels of TET enzymes are significantly reduced in breast cancer, in particular the levels of TET1. In addition, it was demonstrated that $5 \mathrm{hmC}$ levels are reduced in several tissues and are related to breast cancers tumorigenesis [83].

It has also been demonstrated in vivo that TET1 inhibits of the progression of breast cancer cells, whereas the reduced expression of TET1 in patients with breast cancer correlates with poor survival [49]. As mentioned above, vitamin $C$ can activate TETs as a cofactor, and it is required for the optimal activity of TETs.

Moreover, GLUT1 expression is increased in breast cancers with higher grade and proliferative activity, allowing the entry of DHA and its indirect anticancer activity [84].

Finally, vitamin C exerts a powerful anti-inflammatory activity and a immune system stimulation counteracting tumor proliferation, angiogenesis, metastasis, and resistance to therapy [41].

\section{Conclusions}

There are numerous advantages in giving IVC to patients affected by breast cancer, which make it an ideal additional therapy. Cancer patients often have low levels of vitamin C, and IVC provides an efficient strategy to restore the physiological concentrations. Moreover, IVC has been shown to improve QoL in cancer patients. Indeed, both pre-clinical and clinical studies indicate that IVC is able to decrease the toxic side-effects of chemotherapeutic agents without interfering with their anticancer activity, most likely through the antioxidant and anti-inflammatory activities of IVC. 
Funding: This research received no external funding.

Acknowledgments: I am very grateful to Donald Martin, University of Grenoble, France, for English language editing.

Conflicts of Interest: The author declares no conflict of interests.

\section{Abbreviations}

\begin{tabular}{|c|c|}
\hline$\alpha$ KGDDs & $\alpha$-ketoglutarate-dependent dioxygenases \\
\hline $5 \mathrm{caC}$ & 5-carboxyl-cytosine \\
\hline $5 \mathrm{fC}$ & 5-formyl-cytosine \\
\hline $5 \mathrm{hmC}$ & 5-hydroxy-methyl-cytosine \\
\hline $5 \mathrm{mC}$ & 5-methyl-cytosine \\
\hline COX-2 & Cyclooxygenase 2 \\
\hline CSC & Cancer stem cell \\
\hline 2-DG & 2-deoxy- $D$-glucose \\
\hline DHA & Dehydroascorbate \\
\hline DHA & Dehydroascorbic acid \\
\hline $\mathrm{d}-\mathrm{TPP}$ & Dodecyl-tri-phenyl-phosphonium \\
\hline ER & Estrogen receptor \\
\hline EU & European Union \\
\hline GLUT & Glucose transporter \\
\hline GM-CSF & Granulocyte-macrophage colony-stimulating factor \\
\hline $\mathrm{H}_{2} \mathrm{O}_{2}$ & Hydrogen peroxide \\
\hline HER2 & Human epidermal growth factor 2 \\
\hline HIF & Hypoxia-inducible factor \\
\hline HIF-1 $\alpha$ & Hypoxia-inducible factor 1 alpha \\
\hline HIF- $1 \beta$ & Hypoxia-inducible factor 1 beta \\
\hline $\mathrm{HO}^{\bullet}$ & Hydroxyl radicals \\
\hline IFN- $\gamma$ & Interferon gamma \\
\hline IL & Interleukin \\
\hline IVC & Intravenous vitamin $C$ \\
\hline LTED & Long term estrogen deprived \\
\hline MDHA & Monodehydroascorbate \\
\hline NF-kB & Nuclear factor kappa-light-chain-enhancer of activated B cells \\
\hline NK & Natural killer \\
\hline $\mathrm{O} 2{ }^{\bullet-}$ & Peroxide ions \\
\hline P53 & Protein 53 \\
\hline PGE2 & Prostaglandin E2 \\
\hline PR & Progesterone receptor \\
\hline QoL & Quality of life \\
\hline ROS & Reactive oxygen species \\
\hline SVCT & Sodium dependent vitamin $C$ transporters \\
\hline TAM-R & Tamoxifen-resistant \\
\hline TET & Ten eleven translocation proteins \\
\hline TNBC & Triple negative breast cancer \\
\hline TNF- $\alpha$ & Tumor necrosis factor alfa \\
\hline WHO & World Health Organization \\
\hline
\end{tabular}

\section{References}

1. Carioli, G.; Malvezzi, M.; Rodriguez, T.; Bertuccio, P.; Negri, E.; La Vecchia, C. Trends and predictions to 2020 in breast cancer mortality in Europe. Breast 2017, 36, 89-95. [CrossRef] [PubMed]

2. Deshpande, T.M.; Pandey, A.K.; Shyama, S.K. Breast cancer and etiology. Trends Med. 2017, 17, 1-7. [CrossRef]

3. Kim, R.K.; Suh, Y.; Yoo, K.C.; Cui, Y.H.; Kim, H.; Kim, M.J.; Kim, I.G.; Lee, S.J. Activation of KRAS promotes the mesenchymal features of basal-type breast cancer. Exp. Mol. Med. 2015, 47, e137. [CrossRef] [PubMed] 
4. Cameron, E.; Pauling, L.; Leibovitz, B. Ascorbic acid and cancer: A review. Cancer Res. 1979, 39, $663-681$. [PubMed]

5. Zaidi, S.; Hussain, S.; Verma, S.; Veqar, Z.; Khan, A.; Un Nazir, S.; Singh, N.; Ali Moiz, J.; Tanwar, P.; Srivastava, A.; et al. Efficacy of Complementary Therapies in the Quality of Life of Breast Cancer Survivors. Front. Oncol. 2017, 7, 326. [CrossRef] [PubMed]

6. Wyatt, G.; Sikorskii, A.; Wills, C.E.; Su, H. Complementary and alternative medicine use, spending, and quality of life in early stage breast cancer. Nurs Res. 2010, 59, 58-66. [CrossRef]

7. Paciolla, C.; Fortunato, S.; Dipierro, N.; Paradiso, A.; De Leonardis, S.; Mastropasqua, L.; de Pinto, M.C. Vitamin C in Plants: From Functions to Biofortification. Antioxidants 2019, 8, 519. [CrossRef]

8. Du, J.; Cullen, J.J.; Buettner, G.R. Ascorbic acid: Chemistry, biology and treatment of cancer. Biochim. Bio-Phys. Acta 2012, 1826, 443-457. [CrossRef]

9. Wohlrab, C.; Phillips, E.; Dachs, G.U. Vitamin C Transporters in Cancer: Current Understanding and Gaps in Knowledge. Front. Oncol. 2017, 7, 74. [CrossRef]

10. Dewhirst, R.A.; Fry, S.C. The oxidation of dehydroascorbic acid and 2,3-diketogulonate by distinct reactive oxygen species. Biochem. J. 2018, 475, 3451-3470. [CrossRef]

11. Gulcin, İ. Antioxidants and antioxidant methods: An updated overview. Arch. Toxicol. 2020, 94, 651-715. [CrossRef] [PubMed]

12. Gonzalez, M.J.; Miranda-Massari, J.R.; Mora, E.M.; Guzmán, A.; Riordan, N.H.; Riordan, H.D.; Casciari, J.J.; Jackson, J.A.; Román-Franco, A. Orthomolecular Oncology Review: Ascorbic Acid and Cancer 25 Years Later. Integr. Cancer Ther. 2005, 4, 32-44. [CrossRef]

13. Padayatty, S.J.; Levine, M. Vitamin C: The known and the unknown and Goldilocks. Oral Dis. 2016, 22, 463-493. [CrossRef] [PubMed]

14. Smirnoff, N. Ascorbic acid: Metabolism and functions of a multi-facetted molecule. Curr. Opin. Plant. Biol. 2000, 3, 229-235. [CrossRef]

15. Pal, S.; Jana, N.R. Pharmacologic Vitamin C Based Cell Therapy via Iron Oxide Nanoparticle-Induced Intracellular Fenton Reaction. Acs Appl. Nano Mater. 2020, 3, 1683-1692. [CrossRef]

16. Grosso, G.; Bei, R.; Mistretta, A.; Marventano, S.; Calabrese, G.; Masuelli, L.; Giganti, M.G.; Modesti, A.; Galvano, F.; Gazzolo, D. Effects of vitamin C on health: A review of evidence. Front. Biosci. 2013, 18, 1017-1029.

17. Rivas, C.I.; Zuniga, F.A.; Salas-Burgos, A.; Mardones, L.; Ormazabal, V.; Vera, J.C. Vitamin C transporters. J. Physiol. Biochem. 2008, 64, 357-375. [CrossRef]

18. Gromova, O.A.; Torshin, I.Y.; Pronin, A.V.; Kilchevsky, M.A. Synergistic Application of Zinc and Vitamin C to Support Memory and Attention and to Decrease the Risk of Developing Nervous System Diseases. Neurosci. Behav. Physiol. 2019, 4, 357-364. [CrossRef]

19. Tan, B.L.; Norhaizan, M.E.; Liew, W.P.P.; Rahman, H.S. Antioxidant and Oxidative Stress: A Mutual Interplay in Age-Related Diseases. Front. Pharm. 2018, 9, 1162. [CrossRef]

20. Fang, M.; Yuan, J.; Peng, C.; Li, Y. Collagen as a double-edged sword in tumor progression. Tumour. Biol. 2014, 35, 2871-2882. [CrossRef]

21. Mc Cormick, W.J. Cancer: The preconditioning factor in pathogenesis. Arch. Pediat 1954, 71, 313-322.

22. Cameron, E.; Rotman, D. Ascorbic acid, cell proliferation, and cancer. Lancet 1972, 1, 542. [CrossRef]

23. El Attar, T.M.A.; Lin, H.S. Effect of vitamin C on prostaglandin synthesis by fibroblasts and squamous carcinoma cells. Prostaglandins Leukot. Essent. Fat. Acids 1992, 47, 253-257. [CrossRef]

24. Wang, D.; Du Bais, R.N. Prostaglandin and cancer. Gut 2006, 55, 115-122. [CrossRef]

25. Leekha, A.; Gurjar, B.S.; Tyagi, A.; Rizvi, M.A.; Verna, K. Vitamin C in synergism with cisplatin induces cell death in cervical cancer cells through altered redox cycling and p53 upregulation. J. Cancer Res. Clin. Oncol. 2016, 142, 2503-2514.

26. Kim, J.; Lee, S.D.; Chang, B.; Jin, D.H.; Jung, S.I.; Park, M.Y.; Han, Y.; Kim, K.I.; Lim, J.S.; Kang, Y.S.; et al. Enhanced antitumor activity of vitamin C via p53 in cancer cells. Free Radic. Biol. Med. 2012, 53, 1607-1615. [CrossRef]

27. Schoenfeld, J.D.; Sibenaller, Z.A.; Mapuskar, K.A.; Wagner, B.A.; Cramer-Morales, K.L.; Furqan, M. O 2- and H 2 O 2 -Mediated Disruption of Fe Metabolism Causes the Differential Susceptibility of NSCLC and GBM Cancer Cells to Pharmacological Ascorbate. Cancer Cell 2017, 31, 487-500. [CrossRef] 
28. Olney, K.E.; Du, J.; van't Erve, T.J.; Witmer, J.R.; Sibenaller, Z.A.; Wagner, B.A. Inhibitors of hydroperoxide metabolism enhance ascorbate-induced cytotoxicity. Free Radic. Res. 2013, 47, 154-163. [CrossRef] [PubMed]

29. Ibrahim, W.H.; Habib, H.M.; Kamal, H.; St Clair, D.K.; Chow, C.K. Mitochondrial superoxide mediates labile I on level: Evidence from Mn-SOD bgtransgenic mice and heterozygous knockout mice and isolated rat liver mitochondria. Free Radic. Biol. Med. 2013, 65, 143-149. [CrossRef]

30. Lu, Y.X.; Wu, Q.N.; Chen, D.L.; Chen, L.Z.; Wang, Z.X.; Ren, C.; Mo, H.Y.; Chen, Y.; Sheng, H.; Wang, Y.N.; et al. Pharmacological ascorbate suppresses growth of gastric cancer cells with GLUT1 overexpression and enhances the efficacy of oxaliplatin through redox modulation. Theranostics 2018, 8, 1312-1326. [CrossRef]

31. Ge, G.; Peng, D.; Ziying, X.; Guan, B.; Xin, Z.; He, Q.; Zhou, Y.; Li, X.; Zhou, L.; Ci, W. Restoration of 5-hydroxymethylcytosine by ascorbate blocks kidney tumour growth. EMBO Rep. 2018, 19, e45401. [CrossRef]

32. Wu, X.; Zhang, Y. TET-mediated active DNA demethylation: Mechanism, function and beyond. Nat. Rev. Genet. 2017, 18, 517-534. [CrossRef] [PubMed]

33. Hore, T.A. Modulating epigenetic memory through vitamins and TET: Implications for regenerative medicine and cancer treatment. Epigenomics 2017, 9, 863-871. [CrossRef]

34. Yun, J.; Johnson, J.L.; Hanigan, C.L.; Locasale, J.W. Interactions between epigenetics and metabolism in cancers. Front. Oncol. 2012, 15, 163. [CrossRef]

35. Pawlowska, E.; Szczepanska, J.; Blasiak, J. Pro- and Antioxidant Effects of Vitamin C in Cancer in correspondence to Its Dietary and Pharmacological Concentrations. Oxidative Med. Cell. Longev. 2019, 2019, 7286737. [CrossRef]

36. Mastrangelo, D.; Pelosi, E.; Castelli, G.; Lo-Coco, F.; Testa, U. Mechanisms of anti-cancer effects of ascorbate: Cytotoxic activity and epigenetic modulation. Blood Cells Mol. Dis. 2018, 69, 57-64. [CrossRef]

37. Semenza, G.L. Regulation of the breast cancer stem cell phenotype by hypoxia-inducible factors. Clin. Sci. 2015, 129, 1037-1045. [CrossRef] [PubMed]

38. Carr, A.C.; Cook, J. Intravenous Vitamin C for Cancer Therapy-Identifying the Current Gaps in Our Knowledge. Front. Physiol. 2018, 9, 1182. [CrossRef]

39. Gil, M.; Kim, K.E. Interleukin-18 Is a Prognostic Biomarker Correlated with CD8+ T Cell and Natural Killer Cell Infiltration in Skin Cutaneous Melanoma. J. Clin. Med. 2019, 8, 1993. [CrossRef]

40. Rex, D.A.B.; Agarwal, N.; Prasad, T.S.K.; Kandasamy, R.K.; Subbannayya, Y.; Pinto, S.M. A comprehensive pathway map of IL-18-mediated signalling. J. Cell Commun. Signal. 2020, 14, 257-266. [CrossRef]

41. Carr, A.C.; Maggini, S. Vitamin C and Immune Function. Nutrients 2017, 9, 1211. [CrossRef]

42. Härtel, C.; Strunk, T.; Bucsky, P.; Schultz, C. Effects of vitamin C on intracytoplasmic cytokine production in human whole blood monocytes and lymphocytes. Cytokines 2004, 27, 101-106. [CrossRef]

43. Bowie, A.G.; O'Neill, L.A.J. Vitamin C Inhibits NF-kB Activation by TNF Via the Activation of p38 Mitogen-Activated Protein Kinase. J. Immunol. 2000, 165, 7180-7188. [CrossRef]

44. Munoz, E.; Blazquez, M.V.; Ortiz, C.; Gomez-Diaz, C.; Navas, P. Role of ascorbate in the activation of NF-kB by tumor necrosis factor-a in T-cells. Biochem. J. 1997, 325, 23-28. [CrossRef] [PubMed]

45. Bowie, A.G.; Carcamo, J.M.; Pedraza, A.; Borquez-Qjeda, O.; Golde, D.W. Vitamin C suppresses TNFa-induced NFkB activation by inhibiting Ik $\alpha$ B phosphorilation. Biochemistry 2002, 41, 12995-13002. [CrossRef]

46. Greten, F.R.; Grivennikow, S.I. Inflammation and cancer: Triggers, mechanisms, and consequences. Immunity 2019, 51, 27-41. [CrossRef]

47. Chen, Q.; Espey, M.G.; Krishna, M.C.; Mitchell, J.B.; Corpe, C.P.; Buettner, G.R. Pharmacologic ascorbic acid concentrations selectively kill cancer cells: Action as a pro-drug to deliver hydrogen peroxide to tissues. Proc. Natl. Acad. Sci. USA 2005, 102, 13604-13609. [CrossRef]

48. Kurbacher, C.M.; Wagner, U.; Kolster, B.; Andreotti, P.E.; Krebs, D.; Bruckner, H.W. Ascorbic acid (vitamin C) improves the antineoplastic activity of doxorubicin, cisplatin, and paclitaxel in human breast carcinoma cells in vitro. Cancer Lett. 1996, 103, 183-189. [CrossRef]

49. Lee, S.J.; Jeong, J.H.; Lee, I.H.; Lee, J.; Jung, J.H.; Park, H.Y.; Lee, D.H.; Chae, Y.S. Effect of High-dose Vitamin C Combined with Anti-cancer Treatment on Breast Cancer Cells. Anticancer Res. 2019, 39, 751-758. [CrossRef]

50. Hatem, E.; Azzi, S.; El Banna, N.; He, T.; Heneman-Masurel, A.; Vernis, L.; Barlle, D.; Masson, V.; Dingli, F.; Loew, D.; et al. Auranofin/Vitamin C: A Novel Drug Combination Targeting Triple-Negative Breast Cancer. JNCI J. Natl. Cancer Inst. 2019, 111, 597-608. [CrossRef] 
51. Zeng, L.H.; Wang, Q.M.; Feng, L.Y.; Ke, Y.D.; Xu, Q.Z.; Wei, A.Y.; Zhang, C.; Ying, R.B. High-dose vitamin C suppresses the invasion and metastasis of breast cancer cells via inhibiting epithelial-mesenchymal transition. Oncotargets 2019, 12, 7405-7413. [CrossRef]

52. Gan, L.; Camarena, V.; Mustafi, S.; Wang, G. Vitamin C Inhibits Triple-Negative Breast Cancer Metastasis by Affecting the Expression of YAP1 and Synaptopodin 2. Nutrients 2019, 11, 2997. [CrossRef]

53. Hsu, C.H.; Peng, K.L.; Kang, M.L.; Chen, Y.R.; Yang, Y.C.; Tsai, C.H.; Chu, C.S.; Jeng, Y.M.; Chen, Y.T.; Lin, F.M.; et al. TET1 suppresses cancer invasion by activating the tissue inhibitors of metalloproteinases. Cell Rep. 2012, 2, 568-579. [CrossRef]

54. Sant, D.W.; Mustafi, S.; Gustafson, C.B.; Chen, J.; Slingerland, J.M.; Wang, G. Vitamin C promotes apoptosis in breast cancer cells by increasing TRAIL expression. Sci. Rep. 2018, 8, 5306. [CrossRef]

55. Cha, J.; Roomi, M.W.; Ivanov, V.; Kalinovsky, T.; Niedzwiecki, A.; Rath, M. Ascorbate supplementation inhibits growth and metastasis of B16FO melanoma and 4T1 breast cancer cells in vitamin C-deficient mice. Int. J. Oncol. 2013, 42, 55-64. [CrossRef]

56. Park, S.; Yoon, S.Y.; Kim, K.E.; Lee, H.R.; Hur, D.Y.; Song, H.; Kim, D.; Bang, S.I.; Cho, D.H. Interleukin-18 induces transferrin expression in breast cancer cell line MCF-7. Cancer Lett. 2009, 286, 189-195. [CrossRef]

57. De Francesco, E.M.; Ozsvari, B.; Sotgia, F.; Lisanti, M.P. Dodecyl-TPP Targets Mitochondria and Potently Eradicates Cancer Stem Cells (CSCs): Synergy With FDA-Approved Drugs and Natural Compounds (Vitamin C and Berberine). Front. Oncol. 2019, 9, 615. [CrossRef]

58. Tsao, C.S. Inhibiting effect of ascorbic acid on the growth of human mammary tumor xenografts. Am. J. Clin. Nutr. 1991, 54, 1274S-1280S. [CrossRef]

59. McCormick, W.J. Cancer: A collagen disease, secondary to nutrition deficiency. Arch. Pediat. 1959, 76, 166-171.

60. Hoffman, F. Micronutrient requirements of cancer patients. Cancer 1985, 55, 14550. [CrossRef]

61. van Gorkom, G.N.Y.; Lookermans, E.L.; Van Elssen, C.H.M.J.; Bos, G.M.J. The Effect of Vitamin C (Ascorbic Acid) in the Treatment of Patients with Cancer: A Systematic Review. Nutrients 2019, 11, 977. [CrossRef]

62. Carr, A.C.; McCall, C. The role of vitamin C in the treatment of pain: New insights. J. Transl. Med. 2017, 15, 77. [CrossRef] [PubMed]

63. Yeom, C.; Jung, G.; Song, K. Changes of terminal cancer patients health related quality of life after high dose vitamin C administration. Korean Med. Sci. 2007, 22, 7-11. [CrossRef]

64. Vollbracht, C.; Schneider, B.; Leendert, V.; Weiss, G.; Auerbach, L.; Beuth, J. Intravenous vitamin C administration improves quality of life in breast cancer patients during chemo-radiotherapy and aftercare: Results of a retrospective, multicentre, epidemiological cohort study in Germany. In Vivo 2011, 82, 983-990.

65. Hoffer, L.J.; Levine, M.; Assouline, S.; Melnychuk, D.; Padayatty, S.J.; Rosadiuk, K.; Rousseau, C.; Robitaille, L.; Miller, W.H., Jr. Phase I clinical trial of i.v. ascorbic acid in advanced malignancy. Ann. Oncol. 2008, 19, 1969-1974. [CrossRef]

66. Ma, Y.; Chapman, J.; Levine, M.; Polireddy, K.; Drisko, J.; Chen, Q. High-dose parenteral ascorbate enhanced chemosensitivity of ovarian cancer and reduced toxicity of chemotherapy. Sci. Transl. Med. 2014, 6, 222 ra18. [CrossRef]

67. Riordan, H.D.; Casciari, J.J.; Gonzalez, M.J.; Riordan, N.H.; Miranda-Massari, J.R.; Taylor, P.; Jackson, J.A. A pilot clinical study of continuous intravenous ascorbate in terminal cancer patients. P. R. Health Sci. J. 2005, 24, 269-276.

68. Hoffer, L.J.; Robitaille, L.; Zakarian, R.; Melnychuk, D.; Kavan, P.; Agulnik, J.; Cohen, V.; Small, D.; Miller, W.H., Jr. High-dose intravenous vitamin C combined with cytotoxic chemotherapy in patients with advanced cancer: A phase I-II clinical trial. PLoS ONE 2015, 10, e0120228. [CrossRef]

69. Agus, D.B.; Vera, J.C.; Golde, D.W. Stromal cell oxidation: A mechanism by which tumors obtain vitamin C. Cancer Res. 1999, 59, 4555-4558.

70. Raloff, J. Antioxidants may help cancers thrive. Sci. News 2000, 157, 5. [CrossRef]

71. Fromberg, A.; Gutsch, D.; Schulze, D.; Vollbracht, C.; Weiss, G.; Czubayko, F.; Aigner, A. Ascorbate exerts anti-proliferative effects through cell cycle inhibition and sensitizes tumor cells toward cytostatic drugs. Cancer Chemother. Pharm. 2011, 67, 1157-1166. [CrossRef]

72. Shinozaki, K.; Hosokawa, Y.; Hazawa, M.; Kashiwakura, I.; Okumura, K.; Kaku, T.; Nakayama, E. Ascorbic acid enhances radiation-induced apoptosis in an HL60 human leukemia cell line. J. Ratiat. Res. 2011, 52, 229-237. [CrossRef] 
73. Espey, M.; Chen, P.; Chalmers, B.; Drisko, J.; Sun, A.Y.; Levine, M.; Chen, Q. Pharmacologic ascorbate synergizes with gemcitabine in preclinical models of pancreatic cancer. Free Radic. Biol. Med. 2011, 50, 1610-1619. [CrossRef]

74. Simone, C.B.; Simone, N.L.; Simone, V.; Simone, C.B. Antioxidants and other nutrients do not interfere with chemotherapy or radiation therapy and can increase survival, part 1. Atlern. Health Med. 2007, 13, 22-28.

75. Block, K.; Koch, A.C.; Mead, M.N.; Tothy, P.K.; Newman, R.A.; Gyllenhaal, C. Impact of antioxidant supplementaion on chemotherapeutic toxicity: A systematic review of the evidence from randomized controlled trials. Int. J. Cancer 2008, 123, 1227-1239. [CrossRef] [PubMed]

76. Gonzalez, M.J.; Miranda-Massari, J.R. New Insights on Vitamin C and Cancer. In Springer Briefs in Cancer Research; Lau, A., Liu, Y., Tron, A., Inuzuka, H., Wei, W., Eds.; Springer: Berlin/Heidelberg, Germany, 2014.

77. Khanzode, S.S.; Muddeshwar, M.G.; Khanzode, S.D.; Dakhale, G.N. Antioxidant enzymes and lipid peroxidation in different stages of breast cancer. Free Radic. Res. 2004, 38, 81-85. [CrossRef]

78. Reuter, S.; Gupta, S.C.; Chaturvedi, M.M.; Aggarwal, B.B. Oxidative stress, inflammation, and cancer: How are they linked? Free Radic. Biol. Med. 2010, 49, 1603-1616. [CrossRef]

79. Molina-Montes, E.; Salamanca-Fernández, E.; Garcia-Villanova, B.; Sánchez, M.J. The Impact of Plant-Based Dietary Patterns on Cancer-Related Outcomes: A Rapid Review and Meta-Analysis. Nutrients 2020, 12, 2010. [CrossRef] [PubMed]

80. Harrison, H.; Pegg, H.J.; Thompson, J.; Bates, C.; Shore, P. HIF1-alpha expressing cells induce a hypoxic-like response in neighbouring cancer cells. BMC Cancer 2018, 18, 674. [CrossRef]

81. Schito, L.; Semenza, G.L. Hypoxia-Inducible Factors: Master Regulators of Cancer Progression. Trends Cancer 2016, 2, 758-770. [CrossRef]

82. Knowles, H.J.; Raval, R.R.; Harris, A.L.; Ratcliffe, P.J. Effect of ascorbate on the activity of hypoxia-inducible factor in cancer cells. Cancer Res. 2003, 63, 1764-1768.

83. Yang, H.; Liu, Y.; Bai, F.; Zhang, J.Y.; Ma, S.H.; Liu, J.; Xu, Z.D.; Zhu, H.G.; Ling, Z.Q.; Ye, D.; et al. Tumor development is associated with decrease of TET gene expression and 5-methylcytosine hydroxylation. Oncogene 2013, 32, 663-669. [CrossRef]

84. Zambrano, A.; Molt, M.; Uribe, E.; Salas, M. Glut 1 in Cancer Cells and the Inhibitory Action of Resveratrol as a Potential Therapeutic Strategy. Int. J. Mol. Sci. 2019, 20, 3374. [CrossRef]

Publisher's Note: MDPI stays neutral with regard to jurisdictional claims in published maps and institutional affiliations.

(C) 2020 by the author. Licensee MDPI, Basel, Switzerland. This article is an open access article distributed under the terms and conditions of the Creative Commons Attribution (CC BY) license (http://creativecommons.org/licenses/by/4.0/). 